\title{
CONSTANT NORMS AND NUMERICAL RADII OF MATRIX POWERS
}

\author{
Hwa-Long GaU, KuO-Zhong Wang And PeI Yuan Wu
}

\begin{abstract}
For an $n$-by- $n$ complex matrix $A$, we consider conditions on $A$ for which the operator norms $\left\|A^{k}\right\|$ (resp., numerical radii $w\left(A^{k}\right)$ ), $k \geqslant 1$, of powers of $A$ are constant. Among other results, we show that the existence of a unit vector $x$ in $\mathbb{C}^{n}$ satisfying $\left|\left\langle A^{k} x, x\right\rangle\right|=w\left(A^{k}\right)=w(A)$ for $1 \leqslant k \leqslant 4$ is equivalent to the unitary similarity of $A$ to a direct sum $\lambda B \oplus C$, where $|\lambda|=1$, $B$ is idempotent, and $C$ satisfies $w\left(C^{k}\right) \leqslant w(B)$ for $1 \leqslant k \leqslant 4$. This is no longer the case for the norm: there is a 3-by-3 matrix $A$ with $\left\|A^{k} x\right\|=\left\|A^{k}\right\|=\sqrt{2}$ for some unit vector $x$ and for all $k \geqslant 1$, but without any nontrivial direct summand. Nor is it true for constant numerical radii without a common attaining vector. If $A$ is invertible, then the constancy of $\left\|A^{k}\right\|$ (resp., $w\left(A^{k}\right)$ ) for $k= \pm 1, \pm 2, \ldots$ is equivalent to $A$ being unitary. This is not true for invertible operators on an infinite-dimensional Hilbert space.
\end{abstract}

Mathematics subject classification (2010): 15A60, 47A12, 47A30.

Keywords and phrases: Operator norm, numerical radius, idempotent matrix, irreducible matrix.

\section{REFERENCES}

[1] V. ChKLIAR, Numerical radii of simple powers, Linear Algebra Appl., 265 (1997), 119-121.

[2] M. A. DRits Chel AND H. J. Woerdeman, Model theory and linear extreme points in the numerical radius unit ball, Mem. Amer. Math. Soc., 129 (1997).

[3] M. Goldberg, E. TAdmore And G. ZwAS, The numerical radius and spectral matrices, Linear Multilinear Algebra, 2 (1975), 317-326.

[4] P. R. Halmos, A Hilbert Space Problem Book, 2nd ed., Springer, New York, 1982.

[5] R. A. Horn And C. R. Johnson, Topics in Matrix Analysis, Cambridge University Press, Cambridge, 1991.

[6] R. A. Horn And C. R. Johnson, Matrix Analysis, 2nd ed., Cambridge University Press, Cambridge, 2013.

[7] C.-K. LI, B.-S. TAM AND P. Y. WU, The numerical range of a nonnegative matrix, Linear Algebra Appl., 350 (2002), 1-23.

[8] V. PTÁK, Lyapunov equations and Gram matrices, Linear Algebra Appl., 49 (1983), 33-55.

[9] J. G. STAMPFLI, Minimal range theorems for operators with thin spectra, Pacific J. Math., 23 (1967), 601-612.

[10] J. G. STAMPFLI, A local spectral theory for operators, J. Func. Anal., 4 (1969), 1-10.

[11] B. Sz.-NAGY, On uniformly bounded linear transformations in Hilbert space, Acta Sci. Math. (Szeged), 11 (1947), 152-157.

[12] S.-H. Tso AND P. Y. WU, Matricial ranges of quadratic operators, Rocky Mountain J. Math., 29 (1999), 1139-1152.

[13] K.-Z. Wang And P. Y. Wu, Numerical ranges of weighted shifts, J. Math. Anal. Appl., 381 (2011), 897-909.

[14] K.-Z. WANG, P. Y. WU AND H.-L. GAU, Crawford numbers of powers of a matrix, Linear Algebra Appl., 433 (2010), 2243-2254.

[15] J. Wermer, On invariant subspaces of normal operators, Proc. Amer. Math. Soc., 3 (1952), 270-277. 